\title{
Crescimento e partição da biomassa de mudas de mulungu sob adubação fosfatada e inoculação micorrízica
}

\author{
Tiago de Sousa Leite ${ }^{1}$, Rômulo Magno Oliveira de Freitas ${ }^{1}$, Jeferson Luiz Dallabona Dombroski ${ }^{1}$, Moadir de Sousa Leite ${ }^{1}$, \\ Mara Raquel de Oliveira Rodrigues ${ }^{1}$
}

${ }_{1}^{1}$ Universidade Federal Rural do Semi-Árido, Departamento de Ciências Vegetais, Av. Francisco Mota, 572, CEP 59.625-900, Mossoró, RN, Brasil

"Autor correspondente:

gocame@gmail.com

Termos para indexação:

Matéria seca

Área foliar

Índice de qualidade de Dickson

Index terms:

Dry matter

Leaf area

Dickson quality index

Histórico do artigo:

Recebido em 09/01/2014

Aprovado em 14/12/2014

Publicado em 31/12/2014

doi: 10.4336/2014.pfb.34.80.642
Resumo - O objetivo desse estudo foi avaliar o crescimento inicial e partição da biomassa de mudas de mulungu (Erythrina velutina Willd.) submetidas a diferentes doses de fósforo na presença e ausência de fungos micorrízicos arbusculares (FMA's). Foi utilizado o delineamento experimental em blocos ao acaso, num esquema fatorial $5 \times 2$, com quatro blocos e três plantas por unidade experimental. Os tratamentos foram compostos pela combinação de cinco doses de fósforo $(0,50,100,150$ e $200 \mathrm{mg}$ de P.kg de solo $^{-1}$ ), utilizando-se como fonte o adubo superfosfato simples, e presença ou ausência de FMA's. Aos 98 dias após a semeadura (DAS) foram avaliadas as variáveis: altura da parte aérea, diâmetro do colo, número de folhas, índice de conteúdo de clorofila foliar, matéria seca das folhas, caules e raízes, área foliar, índice de qualidade de Dickson e relação altura/diâmetro do colo. A dose de $200 \mathrm{mg} \cdot \mathrm{kg}^{-1}$ de P mostrouse a mais eficiente para produção de mudas de mulungu, mas com uma diminuição significativa na associação biológica dessa espécie com rizobactérias. A distribuição de biomassa entre os órgãos das mudas não foi alterada entre diferentes doses de $\mathrm{P}$, não havendo benefícios na utilização de FMA's até os 98 DAS.

\section{Growth and biomass partitioning of mulungu seedlings in response to phosphorus fertilization and mycorrhizal inoculation}

\begin{abstract}
The objective of this work was to evaluate the initial growth and biomass partitioning of mulungu (Erythrina velutina Willd.) seedlings under different rates of phosphorus in the presence and absence of arbuscular mycorrhizal fungi (FMA's). A randomized blocks design in a $5 \times 2$ factorial arrangement was used, with four replicates and three plants per plot. Treatments consisted of five phosphorus rates $(0$, $50,100,150$ and $\left.200 \mathrm{mg} \cdot \mathrm{kg} \mathrm{soil}^{-1}\right)$, using as source the superphosphate fertilizer, and presence or absence of FMA's. At 98 days after sowing (DAS), shoot height, stem diameter, leaf number, leaf chlorophyll index, leaf dry matter, stem dry matter, root dry matter, leaf area, Dickson quality index and height/stem diameter ratio were evaluated. The phosphorus rate of $200 \mathrm{mg} \cdot \mathrm{kg}^{-1}$ proved to be the most efficient for production of Erythrina velutina seedlings, but with a significant reduction in the biological association of this plant with rhizobacteria. Biomass distribution within the different parts of the plants did not change with distinct rates of $\mathrm{P}$, and there were no benefits in the use of FMA's until 98 DAS.
\end{abstract}




\section{Introdução}

A revegetação de áreas com solos degradados é geralmente uma atividade dispendiosa, com necessidades extremas como a mobilização de camadas férteis de solos de outras áreas, tendo como alternativa de baixo custo a utilização de espécies florestais leguminosas noduladas e micorrizadas (Franco et al., 1992). Como exemplo dessas espécies destaca-se Erythrina velutina Willd., também conhecida por mulungu, canivete, bico-depapagaio, sananduva e corticeira, pertencente à família Fabaceae (Leguminosae-Papilionidae), que é uma árvore de grande resistência à seca, apresentando rusticidade e rápido crescimento (Oliveira et al., 2009).

O mulungu é uma planta decídua e heliófila, característica de várzeas úmidas e margens de rios da Caatinga da região semiárida do Nordeste brasileiro. Apresenta sistema radicular profundo e possui resistência a estresses diversos (Silva et al., 2007). Em sua floração, que ocorre entre os meses de setembro e outubro, a árvore apresenta-se, no semiárido, desfolhada, porém, completamente florida. Sua madeira é leve e pouco resistente a agentes agressivos, com expressiva utilização no artesanato para confecção de tamancos, brinquedos, caixotes, dentre outros (Lorenzi \& Matos, 2002). Trata-se de uma planta muito utilizada em práticas de reflorestamento. Entretanto, pouco se sabe sobre as exigências nutricionais da mesma, ou características biológicas, o que se torna um fator limitante ao sucesso nos processos que envolvem seu cultivo.

A técnica de produção de mudas de espécies arbóreas nativas, para reflorestamento ou recomposição de áreas degradadas, é de suma importância para o uso em programas de recuperação de áreas devastadas, tendo como finalidade a diminuição do impacto ambiental, a melhoria das condições edafoclimáticas e a conservação da biodiversidade (Carneiro et al., 2004). Dentro dessa técnica se faz necessário o conhecimento das exigências nutricionais das espécies envolvidas, bem como suas características biológicas a exemplo das associações micorrízicas.

Fungos micorrízicos arbusculares (FMA's) são organismos benéficos às plantas, que se associam às raízes e proporcionam redução de danos no transplante, maior índice de pegamento das mudas, redução no tempo de formação, aumento na absorção de alguns nutrientes, em especial o fósforo, e maior produção de substâncias de reserva (Silveira et al., 2002; Arango et al., 2012). Isso é possível porque as hifas desses fungos comportam-se como pelos radiculares, aumentando a área de absorção de nutrientes das raízes e o volume de solo explorado. FMA's são fungos da ordem Glomales (Glomeromycota) e têm ocorrência generalizada nas plantas vasculares (Pereira et al., 1996), a exemplo do mulungu.

Para Ceconi et al. (2007), a fase de produção de mudas é fundamental para o estabelecimento de plantas adultas bem nutridas e formadas, e a obtenção de mudas de boa qualidade exige a utilização de substrato que forneça os nutrientes necessários ao pleno desenvolvimento da planta. Mas em viveiros para produção de mudas é comum o uso de substratos pobres em nutrientes ou não balanceados, ocasionando baixa qualidade das mudas e comprometendo o desempenho em campo.

No caso de P, os povoamentos florestais brasileiros têm sido implantados em solos onde normalmente este nutriente é um dos mais limitantes do crescimento vegetal. Muitas vezes, na produção de mudas utiliza-se subsolo como substrato, cuja fertilidade natural é extremamente baixa (Schumacher et al., 2004; Lima et al., 2008). Nesse sentido, a associação das plantas com FMA's tende a minorar esse problema. Seus benefícios à planta hospedeira são a melhoria das condições nutricionais, em especial de $\mathrm{P}$, e a tolerância a estresses diversos, principalmente estresse hídrico (Carneiro et al., 2004).

Brondani et al. (2008), estudando produção de mudas de Bauhinia forficata em tubetes, no estado do Paraná, chegaram à conclusão de que esta espécie apresenta em seu crescimento resposta positiva ao incremento da dose de fósforo no substrato utilizado, enfatizando a importância desse elemento no crescimento inicial. Chaves \& Borges (2005) trabalhando no estado de Minas Gerais com Dalbergia nigra concluíram que mudas inoculadas com FMA's, quando comparadas àquelas não inoculadas, apresentaram maior eficiência de utilização de $\mathrm{P}$ e maior eficiência do sistema radicular na absorção e translocação de $\mathrm{P}$ para a parte aérea.

Nesse contexto, este trabalho teve por objetivo avaliar o crescimento inicial e a partição da biomassa de mudas de mulungu (Erythrina velutina) submetidas a diferentes doses de fósforo na presença e ausência de fungos micorrízicos arbusculares.

\section{Material e métodos}

O experimento foi conduzido no período de janeiro a maio de 2013, no viveiro de mudas do Departamento de Ciências Vegetais da Universidade Federal Rural 
do Semi-Árido (UFERSA), situada no Município de Mossoró, RN, com coordenadas geográficas $5^{\circ} 11^{\prime}$ de latitude sul, 37²0' de longitude W. Gr., com $18 \mathrm{~m}$ de altitude, temperatura média anual em torno de $27,5^{\circ} \mathrm{C}$, umidade relativa de $68,9 \%$, nebulosidade média anual de 4,4 décimos e precipitação média anual de 673,9 $\mathrm{mm}$, com clima quente e seco (Carmo Filho et al., 1991). Durante a condução do experimento verificouse, dentro do viveiro com sombreamento de $50 \%$ de luz, temperatura e umidade relativa média de $31,4^{\circ} \mathrm{C}$ e $60,7 \%$, respectivamente.

Foi utilizado o delineamento experimental em blocos ao acaso, num esquema fatorial $5 \times 2$, com quatro blocos e três plantas por unidade experimental. Os tratamentos foram compostos pela combinação de cinco doses de fósforo $\left(0,50,100,150\right.$ e $200 \mathrm{mg}$ de P.kg de solo $\left.{ }^{-1}\right)$ e presença ou ausência de FMA's. Para P, foi utilizado como fonte o adubo superfosfato simples. Já para a adição das micorrizas, foi coletado solo micorrizado de uma área infestada com grama-seda (Cynodon dactylon) na própria Universidade, através da retirada de solo da rizosfera das plantas, sendo adicionado como inóculo 20 $\mathrm{g}$ do mesmo às sacolas dos tratamentos, contendo valores superiores a 20 esporos por grama de inóculo e raízes colonizadas com hifas de FMAs. A contagem de esporos foi realizada em microscópio ótico, após extração pelo método de peneiramento úmido (Gerdemann \& Nicholson, 1963) e centrifugação em sacarose (Jenkins, 1964).

Para o substrato utilizado, constituído de solo da região, a análise física revelou a seguinte granulometria: areia total $=0,87 \mathrm{~kg} \mathrm{~kg}^{-1}$; silte $=0,09 \mathrm{~kg} \cdot \mathrm{kg}^{-1}$; argila $=$ $0,04 \mathrm{~kg} \cdot \mathrm{kg}^{-1}$. As análises químicas do solo apresentaram: pH (água) de 8,28; $\mathrm{CE}$ de 0,13 dS.m ${ }^{-1}$; matéria orgânica de 11,36 e $\mathrm{N}$ de 0,35 g.kg-1 ; $\mathrm{P}$ de $25,8, \mathrm{~K}^{+}$de 98,85 e $\mathrm{Na}^{+}$de 95 mg. $\mathrm{dm}^{-3} ; \mathrm{Ca}^{2+}$ de 3,2 e $\mathrm{Mg}^{2+}$ de 0,48 cmol . $\mathrm{dm}^{-3}$; Cu de 0,06, Fe de 2,2, Mn de 11,3, e 3,63 mg. $\mathrm{dm}^{-3}$.

As sementes de mulungu utilizadas foram coletadas dentro da UFERSA (Campus Mossoró, RN), sendo beneficiadas no Centro de Pesquisas Vegetais (CPV) da referida Universidade. Para quebra de dormência das sementes foi utilizada a técnica de escarificação manual com lixa d'água n. 80 na porção basal da semente (Silva et al., 2007). Foram utilizadas sacolas plásticas de 1,5 L de volume, sendo colocadas duas sementes por sacola. Aos 10 dias após a semeadura (DAS) foi realizado o desbaste, mantendo-se apenas uma planta por sacola. A irrigação foi realizada duas vezes ao dia (final da tarde e início da manhã) quando as mudas estavam no estágio inicial, sendo posteriormente realizada uma única vez (final da tarde). A cada irrigação, cada parcela recebeu o equivalente a $500 \mathrm{~mL}$ de água, sendo que na fase inicial esse valor era de $200 \mathrm{~mL}$. Para disposição das sacolas, foram utilizados tijolos para isolamento do solo da estufa, evitando contato das raízes com o mesmo.

Decorridos 98 DAS, foram realizadas avaliações das variáveis: altura da parte aérea (APA), diâmetro do colo (DC) e número de folhas (NF). A APA foi obtida com o auxílio de uma régua, enquanto o DC foi medido com o auxílio de um paquímetro digital. Também foi mensurado o índice de conteúdo de clorofila (ICC) através de um medidor portátil de clorofilas CCM-200 (Opti-Sciences, Tyngsboro, Massachusetts, USA), realizando-se duas leituras por planta, sempre nas $3^{\mathrm{a}}$ e $4^{\mathrm{a}}$ folhas de cada planta, a contar a partir do ápice, sempre nos folíolos terminais das folhas.

Posteriormente, foi mensurada a área foliar (AF) através do método do disco corrigido (Souza et al., 2012). Para isso foram retirados 10 discos de área previamente conhecida $\left(5,35 \mathrm{~cm}^{2}\right)$ de maneira aleatória de cada planta. Além da área, também foi determinada a matéria seca desses discos. Com base na área e peso médio dos discos e na matéria seca das folhas, a AF por planta foi calculada através de uma regra de três simples. Esse valor obtido foi multiplicado por um fator de correção, obtido pela correlação $\left(\mathrm{R}^{2}=0,99\right)$ entre os valores de área obtidos pelo método do disco e pelo escaneamento (em escâner de mesa) e posterior análise de 15 folhas no programa gratuito de análise de imagens ImageJ (Schneider et al., 2012).

Os dados de matéria seca foram obtidos através do fracionamento das plantas em folhas (MSF), caule (MSC) e raízes (MSR). Dessa forma, essas frações foram postas para secar em estufa de circulação de ar forçada à temperatura de $65{ }^{\circ} \mathrm{C}$ por três dias, até atingirem massa constante. Cada repetição foi formada por duas plantas representativas. Com base nos dados obtidos, foi determinado o índice de qualidade de Dickson (IQD), seguindo recomendações de Dickson et al. (1960).

Os resultados obtidos foram submetidos à análise de variância pelo teste $\mathrm{F}$, a $5 \%$ de probabilidade, com o auxílio do programa estatístico Sistema para Análise de Variância-SISVAR (Ferreira, 2011), para determinação dos efeitos dos tratamentos e das interações. Em caso de significância, os tratamentos quantitativos foram submetidos a análises de regressões polinomiais, 
utilizando-se o software Sigmaplot 11.0. Na escolha do modelo, levou-se em consideração a explicação biológica e a significância do quadrado médio e das estimativas dos parâmetros.

\section{Resultados e discussão}

Houve efeito significativo das doses de P para todas as variáveis estudadas (Tabela1), não sendo verificados efeitos da inoculação e da interação entre a inoculação $\mathrm{e}$ as doses de $\mathrm{P}$.

Observou-se aos 98 dias incremento significativo para APA, DC, NF e relação altura/diâmetro do colo (A/DC), em função do aumento das doses de fósforo (Figura 1), porém, não foi verificada interação significativa entre os fatores doses e inoculação com fungos micorrízicos. Para APA (Figura 1A), NF (Figura 1C) e A/DC (Figura 1D), os resultados obedeceram a um modelo linear de crescimento a partir do aumento das doses de $\mathrm{P}$, sendo que com a dose de $200 \mathrm{mg} . \mathrm{kg}^{-1}$ de $\mathrm{P}$ observou-se os maiores valores em relação às plantas que não receberam adubação. No caso do DC (Figura 1B), as respostas observadas se ajustaram a um modelo quadrático, onde o pico máximo da curva ocorreu na dose de $150 \mathrm{mg} \cdot \mathrm{kg}^{-1}$ de P.

Plantas adubadas com as doses de 50,100, 150 e 200 mg. $\mathrm{kg}^{-1}$ de P mostraram incrementos aproximados de $6,13,19$ e $25 \%$ na APA, respectivamente, quando comparadas às plantas não adubadas. Também foi verificado um aumento no $\mathrm{NF}$ e na relação $\mathrm{A} / \mathrm{DC}$, onde na primeira variável as doses crescentes de $\mathrm{P}$ proporcionaram valores $3,6,8$ e $11 \%$ superiores às plantas não adubadas, e de 4, 7, 11 e 14\% superiores na segunda variável. Em relação ao DC, o maior aumento foi registrado para a dose de $150 \mathrm{mg} \cdot \mathrm{kg}^{-1}$, a qual proporcionou um incremento de aproximadamente $11 \%$ para essa variável em relação às plantas não adubadas.

$\mathrm{Na}$ produção de mudas, Ceconi et al. (2006), bem como Costa Filho et al. (2013) afirmam que pesquisas envolvendo este processo são de fundamental importância, pois o sucesso de um povoamento florestal está diretamente correlacionado com a qualidade das mudas que são levadas a campo. E dentre as variáveis que determinam esta qualidade estão a altura, o diâmetro do colo, o peso da parte aérea e das raízes e as correlações entre estes. Ceconi et al. (2006) lembra ainda que o desempenho em campo das mudas se dá com maior efetividade nas plantas que apresentam as maiores dimensões entre essas variáveis determinadoras de qualidade das mudas.

É possível observar que a dose de $200 \mathrm{mg} \cdot \mathrm{kg}^{-1}$ de $\mathrm{P}$ foi a que se mostrou mais eficiente, pelos acréscimos apresentados nos valores das variáveis avaliadas (Figura 1). Entretanto, para essas variáveis, os incrementos foram, em geral, relativamente baixos. Para todas as variáveis avaliadas não foram verificadas diferenças estatisticamente significativas entre as plantas com e sem a presença de micorrizas, não havendo interação significativa entre os fatores.

Mello et al. (2008) em suas pesquisas no sul do Brasil com Acacia mearnsii citam que as micorrizas arbusculares são geralmente inibidas em condições de elevada disponibilidade de fósforo, enfatizando que a adição de $\mathrm{P}$ suficiente para otimizar o crescimento das mudas pode reduzir a colonização, o que fundamenta os resultados aqui obtidos. Resultados semelhantes foram verificados por Carneiro et al. (2004), que trabalhando com adubação fosfatada e inoculação com FMA's no

Tabela 1. Resumo da análise de variância (valores de F) para as variáveis matéria seca das folhas (MSF), caule (MSC), raízes (MSR), nódulos (MSN) e total (MST), área foliar (AF), número de folhas (NF), diâmetro do colo (DC), altura da parte aérea (APA), índice de qualidade de Dickson (IQD), relação altura/diâmetro do colo (A/DC) e índice de conteúdo de clorofila (ICC).

\begin{tabular}{|c|c|c|c|c|c|c|c|c|c|c|c|c|c|}
\hline \multirow{2}{*}{ FV } & \multirow{2}{*}{ GL } & \multicolumn{12}{|c|}{ Valores de F } \\
\hline & & MSF & MSC & MSR & MSN & MST & $\mathbf{A F}$ & NF & DC & APA & IQD & $\mathbf{A} / \mathbf{D C}$ & ICC \\
\hline I & 1 & 1,43 & 0,00 & 0,12 & 3,11 & 0,09 & 1,33 & 0,379 & 0,28 & 0,18 & 0,17 & 0,18 & 0,93 \\
\hline $\mathrm{D}$ & 4 & $8,13^{* *}$ & $4,26^{* *}$ & $7,55^{* *}$ & $7,00^{* *}$ & $6,78^{* *}$ & $6,46^{* *}$ & 2,76 & $3,20^{*}$ & $5,82^{* *}$ & $3,21^{*}$ & $3,26^{*}$ & $8,56^{* *}$ \\
\hline $\mathrm{IxD}$ & 4 & 0,54 & 0,66 & 0,49 & 0,96 & 0,53 & 0,40 & 0,17 & 1,73 & 0,58 & 0,99 & 1,30 & 0,27 \\
\hline Erro & 27 & - & - & - & - & - & - & - & - & - & - & - & - \\
\hline Média & - & 3,57 & 9,74 & 2,78 & 0,28 & 13,36 & 1119 & 14,65 & 14,84 & 44,37 & 5,17 & 2,99 & 18,62 \\
\hline $\mathrm{CV}(\%)$ & - & 15,54 & 17,83 & 16,18 & 35,94 & 14,5 & 16,40 & 10,17 & 6,77 & 11,23 & 16,27 & 10,29 & 9,00 \\
\hline
\end{tabular}

$* *,{ }^{*}=$ Efeito significativo pelo teste $\mathrm{F}$ ao nível de $1 \%$ e $5 \%$ de probabilidade, respectivamente; $\mathrm{I}=$ Inoculação; D = Doses. 
estabelecimento de mudas de Cecropia pachystachya na região sudeste verificou que esta espécie, em condições de altos teores de $\mathrm{P}$ disponível, não responde à inoculação com FMA's. Ele ainda afirma que a inoculação com fungos micorrízicos arbusculares, no substrato utilizado para produção de mudas desta espécie, apresenta pouco efeito no estágio inicial das plantas, sendo verificado efeito mais significativo quando estas são transplantadas para o campo, aumentando o vigor das mesmas e facilitando o seu estabelecimento no ambiente.
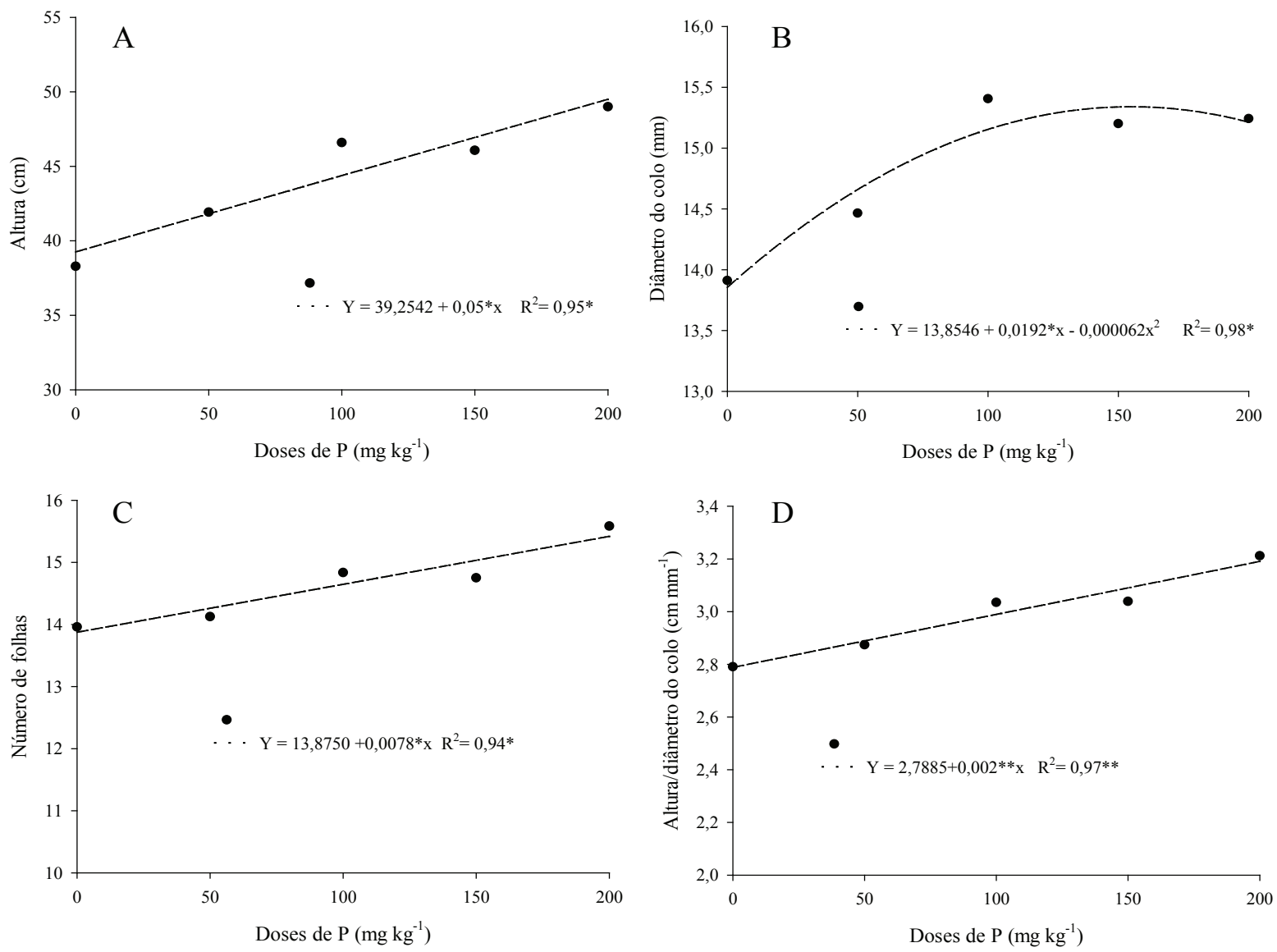

Figura 1. Altura da parte aérea (A), diâmetro do colo (B), número de folhas (C) e relação altura/diâmetro do colo (D) em mudas de mulungu (Erythrina velutina) em função de diferentes doses de fósforo, com quatro repetições, aos 98 dias após a semeadura.

Verificou-se para MSF, MSC e MSR respostas lineares crescentes em função do aumento na dose de P (Figura 2A). Consequentemente, a MST também apresentou este mesmo comportamento. Para a dose de 200 mg.kg-1 o acréscimo na MSF foi em torno de $47 \%$ com relação às plantas não adubadas. Para as demais doses, de 50,100 e $150 \mathrm{mg} \cdot \mathrm{kg}^{-1}$, os valores observados foram 12, 24 e 35\%, respectivamente. Para a MSC os incrementos observados nas plantas adubadas em relação às plantas não adubadas foram $9,19,28$ e $38 \%$, acompanhando o aumento da dose. Esses mesmos incrementos foram verificados para MST. Já no caso da MSR, observaram-se aumentos de aproximadamente 10, 21, 31 e $42 \%$.

Durante a avaliação das plantas, foi constatada a presença de nódulos nas raízes das mesmas, relativos à presença de bactérias do gênero Rhizobium. Os nódulos foram encontrados em estado ativo, mas com quantidade inversamente proporcional à dose de fosfato (Figura 2B). Desse modo, foi verificada resposta linear negativa na matéria seca dos nódulos em relação ao incremento da 
adubação. Para as doses de 50, 100, 150 e 200 mg.kg-1 de $\mathrm{P}$, houveram decréscimos de 13, 26, 40 e 53\% na matéria seca dos nódulos em relação às plantas onde $\mathrm{o}$ $\mathrm{P}$ não foi utilizado.

Pode-se observar que a dose de $200 \mathrm{mg} \cdot \mathrm{kg}^{-1}$ foi superior às demais em relação ao aumento em matéria seca. Esta foi também a dose ideal para produção de matéria seca da parte aérea de Mimosa caesalpiniifolia, encontrada por Oliveira \& Alixandre (2013), que trabalharam no estado do Piauí com parâmetros biométricos de mudas de sabiá micorrizadas sob níveis de fósforo em Latossolo Amarelo.
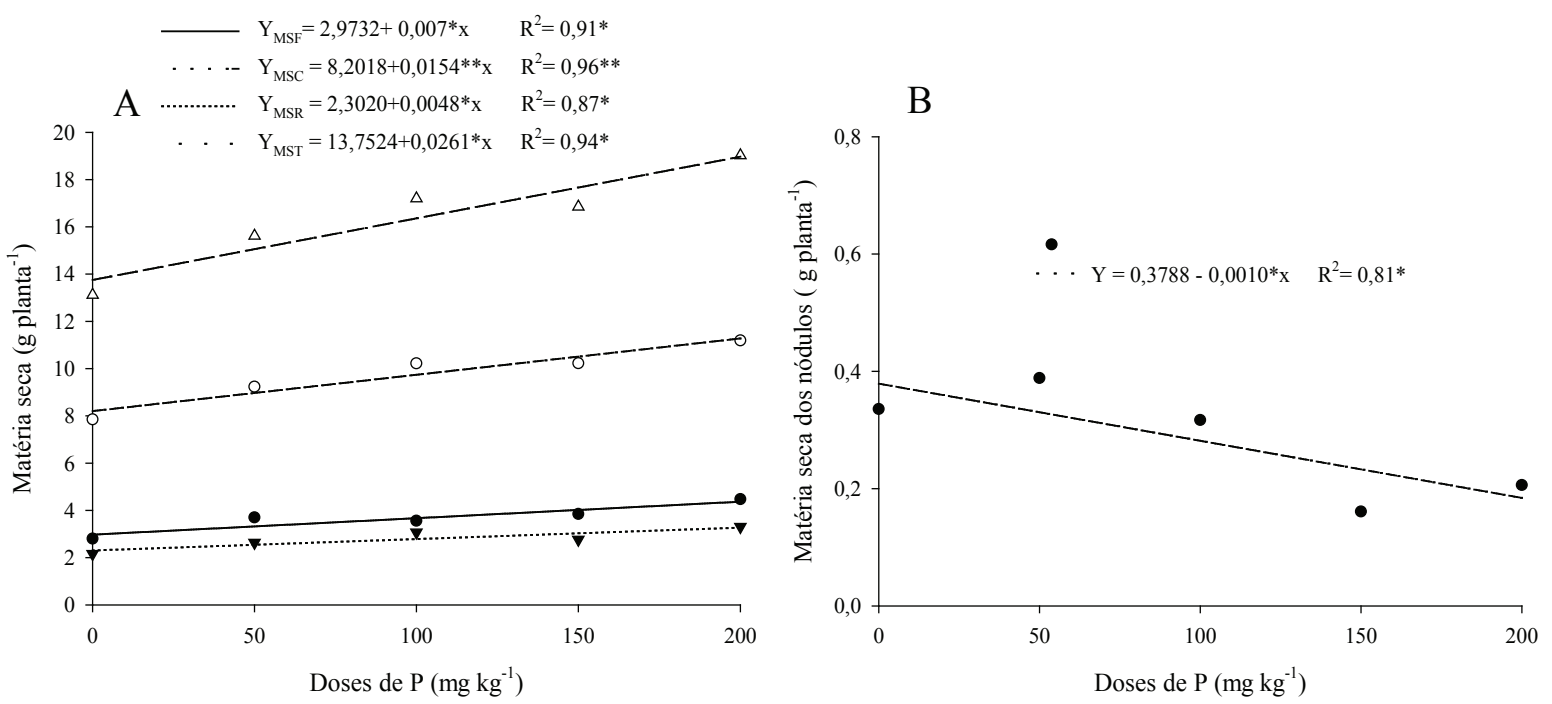

Figura 2. Matéria seca das folhas, matéria seca dos caules, matéria seca das raízes e matéria seca total (A) e matéria seca dos nódulos (B) em mudas de mulungu (Erythrina velutina) em função de diferentes doses de fósforo, com quatro repetições, aos 98 dias após a semeadura.

A distribuição da biomassa entre os diferentes órgãos de mudas de mulungu seguiu um padrão semelhante, independente de doses ou presença e ausência de fungos micorrízicos. Observa-se, na Figura 3A, que o comportamento foi semelhante para todas as doses. Contudo, visto que devem ser buscadas nas plantas características favoráveis à prática de recuperação de áreas degradadas, como a associação com bactérias do gênero Rhizobium (Franco et al., 1992), doses elevadas de fósforo podem acarretar um baixo desenvolvimento da planta em campo. Foi observado que a partir da dose de $150 \mathrm{mg} \cdot \mathrm{kg}^{-1}$, houve uma redução em $40 \%$ na matéria seca de nódulos radiculares em relação às plantas não adubadas.

O conhecimento da área foliar é de suma importância na avaliação de crescimento e desenvolvimento de uma planta, por estar diretamente relacionada com a atividade fotossintética da mesma (Souza et al., 2012). Foi observado efeito linear crescente da AF (Figura 3B) em função do aumento das doses de P. Os incrementos observados em AF com as doses de 50,100,150 e 200 $\mathrm{mg} \cdot \mathrm{kg}^{-1} \mathrm{de} \mathrm{P}$ em relação às plantas não adubadas foram em torno de $11,21,32$ e $43 \%$, respectivamente. O aumento na dose de fósforo também afetou o índice de conteúdo de clorofila (ICC) das mudas de mulungu de forma diretamente proporcional, onde os resultados se ajustaram a um modelo quadrático (Figura 3C). O ICC também atingiu o seu máximo na dose de $200 \mathrm{mg} \cdot \mathrm{kg}^{-1}$ de $\mathrm{P}$, mas com baixos incrementos a partir da dose de $100 \mathrm{mg} . \mathrm{kg}^{-1}$ de P. Os acréscimos proporcionados pelas doses já referidas foram de aproximadamente 11, 19, 25 e $26 \%$ em relação às plantas não adubadas.

Melo \& Cunha (2008), em trabalho envolvendo o crescimento inicial de mudas de Erythrina velutina sob diferentes níveis de luminosidade no estado da Paraíba, ressaltam a importância do índice de qualidade de Dickson (IQD) como promissora medida morfológica ponderada, além de bom índice de qualidade de mudas, 
pois leva em consideração para o seu cálculo a robustez e o equilíbrio da distribuição da biomassa da muda, ponderando vários parâmetros considerados importantes, permitindo predizer consideravelmente a qualidade das mudas ainda no viveiro.

Esse índice se faz necessário nesse tipo de estudo, pois Cruz et al. (2011) concluíram que o fósforo foi o nutriente que promoveu mais efeitos significativos no crescimento e qualidade de mudas de Peltophorum dubium no sudeste. Dentre os parâmetros abordados por esse índice está a MST, a qual cresce proporcionalmente ao índice. Essa informação corrobora os resultados aqui obtidos, onde se verificou que o IQD (Figura 3D) apresentou efeito linear crescente e foi superior para a dose de $200 \mathrm{mg} \cdot \mathrm{kg}^{-1}$, superando o tratamento sem adubação em pouco mais de $17 \%$.
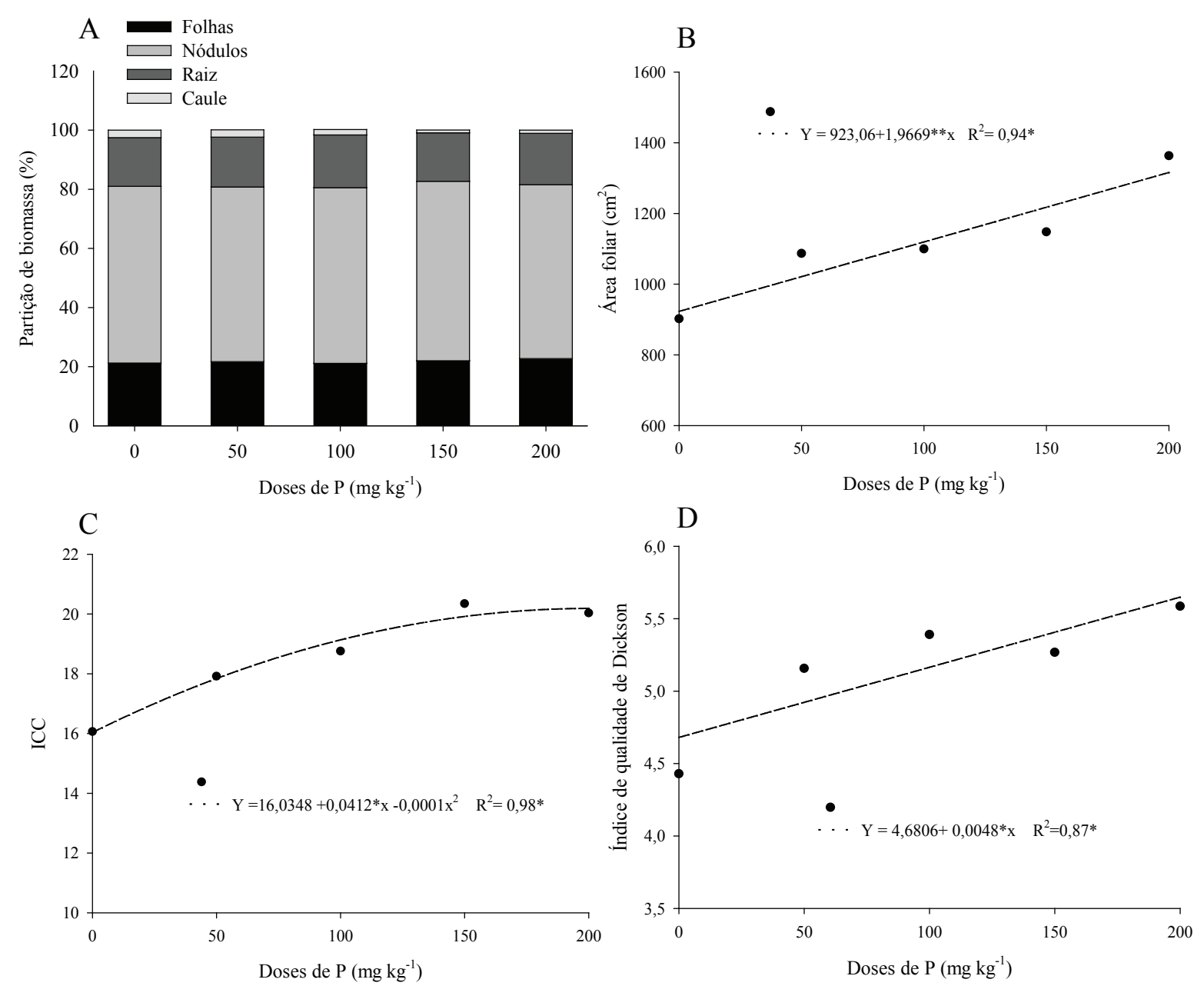

Figura 3. Partição de biomassa (A), área foliar (B), índice de conteúdo de clorofila (C) e índice de qualidade de Dickson (D) em mudas de mulungu (Erythrina velutina) em função de diferentes doses de fósforo, com quatro repetições, aos 98 dias após a semeadura. 


\section{Conclusões}

A dose de $200 \mathrm{mg} \cdot \mathrm{kg}^{-1}$ de P é a mais eficiente para produção de mudas de mulungu (Erythrina velutina) no município de Mossoró, RN, mas proporciona uma diminuição significativa na associação biológica dessa espécie com rizobactérias.

A distribuição de biomassa entre os órgãos de mudas jovens de mulungu não apresenta diferença entre doses de $\mathrm{P}$ distintas.

Não há benefícios na utilização de fungos micorrízicos arbusculares para a produção de mudas de mulungu até a idade de 98 DAS.

\section{Referências}

ARANGO, M. C.; RUSCITTI, M. F.; RONCO, M. G.; BELTRANO, J. Mycorrhizal fungi inoculation and phosphorus fertilizer on growth, essential oil production and nutrient uptake in peppermint (Mentha piperita L.). Revista Brasileira de Plantas Medicinais, Botucatu, v. 14, n. 4, p. 692-699, 2012. DOI: 10.1590/S151605722012000400018 .

BRONDANI, G. E.; SILVA, A. J. C.; ARAUJO, M. A.; GROSSI, F.; WENDLING, I.; CARPANEZZI, A. A. Phosphorus nutrition in the growth of Bauhinia forficata L. seedlings. Acta Scientiarum Agronomy. Maringá, v. 30, supl. p. 665-671, 2008. DOI: 10.4025/ actasciagron.v30i5.787.

CARMO FILHO, F.; ESPÍNOLA SOBRINHO, J.; MAIA NETO, J. M. Dados climatológicos de Mossoró: um município semi-árido nordestino. Mossoró: UFERSA, 1991. 121 p. (Coleção Mossoroense, C.30).

CARNEIRO, M. A. C.; SIQUEIRA, J. O.; DAVIDE, A. C. Fósforo e inoculação com fungos micorrízicos arbusculares no estabelecimento de mudas de embaúba (Cecropia pachystachya Trec). Pesquisa Agropecuária Tropical, Goiânia, v. 34, n. 3, p. 119-125, set./dez. 2004.

CECONI, D. E.; POlleto, I.; BRUN, E. J.; LOVATO, T. Crescimento de mudas de açoita-cavalo (Luehea divaricata Mart.) sob influência da adubação fosfatada. Cerne, Lavras, v. 12, n. 3, p. 292-299, jul./set. 2006.

CECONI, D. E.; POLleto, I.; LOVATO, T.; MUNIZ, M. F. B. Exigência nutricional de mudas de erva-mate (Ilex paraguariensis A. St.-Hil.) à adubação fosfatada. Ciência Florestal, Santa Maria, RS, v. 17, n. 1, p. 25-32, jan./mar. 2007.

CHAVES, L. F. C.; BORGES, R. C. G. Eficiência micorrízica na produção de mudas de jacarandá-da-bahia cultivadas em diferentes doses de fósforo. Acta Scientiarum. Biological Sciences, Maringá, v. 27 , n. 4 , p. $587-594$, out./dez. 2005.

COSTA FILHO, R. T.; VALERI, S. V.; CRUZ, M. C. P. Calagem e adubação fosfatada no crescimento de mudas de Mimosa caesalpiniifolia Benth. em latossolo vermelho-amarelo. Ciência Florestal, Santa Maria, RS, v. 23, n. 1, p. 89-98, jan./mar. 2013. DOI: $10.5902 / 198050988442$.
CRUZ, C. A. F.; PAIVA, H. N.; CUNHA, A. C. M. C. M.; NEVES, J. C. L. Macronutrientes na produção de mudas de canafístula em argissolo vermelho amarelo da região da Zona da Mata, MG. Ciência Florestal, Santa Maria, RS, v. 21, n. 3, p. 445-457, jul./set. 2011.

DICKSON, A.; LEAF, A. L.; HOSNER, J. F. Quality appraisal of white spruce and white pine seedling stock in nurseries. Forest Chronicle, Mattawa, v. 36, p. 10-13, mar. 1960.

FERREIRA, D. F. Sisvar: a computer statistical analysis system. Ciência e Agrotecnologia, Lavras, v. 35, n. 6, p. 1039-1042, nov./ dez. 2011. DOI: 10.1590/S1413-70542011000600001.

FRANCO, A. A.; CAMPELO, E. F.; SILVA, E. M. R.; FARIA, S. M. Revegetação de solos degradados. Seropédica: EMBRAPACNPBS, 1992. 11 p. (EMBRAPA-CNPB. Comunicado Técnico, 9).

GERDEMANN, J. W.; NICOLSON, T. H. Spores of mycorrhizal Endogone species extracted from soil by wet sieving and decanting. Transactions of the British Mycological Society, London, v. 46, p. 235-244, jun. 1963. DOI: 10.1016/S0007-1536(63)80079-0.

JENKINS, W.R. A rapid centrifugal-flotation technique for separating nematodes from soil. Plant Disease Report, Illinois, v. 48, p. 692 694, 1964

LIMA, L. S. H.; FRANCO, E. T. H.; SCHUMACHER, M. V. Crescimento de mudas de Euterpe edulis Martius em resposta a diferentes doses de fósforo. Ciência Florestal, Santa Maria, RS, v. 18, n. 4, p. 461-470, out./dez. 2008.

LORENZI, H.; MATOS, F. J. A. Plantas medicinais no Brasil: nativas e exóticas cultivadas. Nova Odessa, SP: Instituto Plantarum, 2002. $512 \mathrm{p}$

MELLO, A. H.; KAMINSKI, J.; ANTONIOLLI, Z. I.; SANTOS, L. C.; SOUZA, E. L.; SCHIRMER, G. K.; GOULART, R. M. Influência de substratos e fósforo na produção de mudas micorrizadas de Acacia mearnsii de Wild. Ciência Florestal, Santa Maria, RS, v. 18, n. 3, p. 321-327, jul./set. 2008.

MELO, R. R.; CUNHA, M. C. L. Crescimento inicial de mudas de mulungu (Erythrina velutina Wild.) sob diferentes níveis de luminosidade. Ambiência, Guarapuava, v. 4, n. 1, p. 67-77, jan./ abr. 2008 .

OLIVEIRA, J. J. F.; ALIXANDRE, T. F. Parâmetros biométricos de mudas de sabiá micorrizadas sob níveis de fósforo em Latossolo Amarelo. Pesquisa Florestal Brasileira, Colombo, v. 33, n. 74, p. 159-167, abr./jun. 2013. DOI: 10.4336/2013.pfb.33.74.467.

OLIVEIRA, M. D. M.; NASCIMENTO, L. C.; ALVES, E. U.; GONÇALVES, E. P.; GUEDES, R. S. Tratamentos térmico e químico em sementes de mulungu e efeitos sobre a qualidade sanitária e fisiológica. Revista Caatinga, Mossoró, v. 22, n. 3, p. 150-155, jul./set. 2009.

PEREIRA, E. G.; SIQUEIRA, J. O.; CURI, N.; MOREIRA, F. M. S.; PURCINO, A. A. C. Efeitos da micorriza e do suprimento de fósforo na atividade enzimática e na resposta de espécies arbóreas ao nitrogênio. Revista Brasileira de Fisiologia Vegetal, Londrina, v. 8, n. 1, p. $59-65,1996$.

SCHNEIDER, C. A.; RASBAND, W. S.; ELICEIRI, K.W. NIH Image to Image J: 25 years of image analysis. Nature Methods, New York, v. 9, n. 7, p. 671-675, 2012. 
SCHUMACHER, M. V.; CECONI, D. E.; SANTANA, C. A. Influência de diferentes doses de fósforo no crescimento de mudas de angico-vermelho (Parapiptadenia rigida (Bentham) Brenan). Revista Árvore, Viçosa, MG, v. 28, n. 1, p. 149-155, jan./fev. 2004. DOI: 10.1590/S0100-67622004000100019.

SILVA, K. B.; ALVES, E. U.; BRUNO, R. L. A.; GONÇALVES, E. P.; BRAZ, M. S. S.; VIANA, J. S. Quebra de dormência em sementes de Erythryna velutina Willd. Revista Brasileira de Biociências, Porto Alegre, v. 5, supl. 2, p. 180-182, jul. 2007.
SILVEIRA, S. V.; SOUZA, P. V. D.; KOLLER, O. C. Efeito de fungos micorrízicos arbusculares no desenvolvimento do abacateiro. Pesquisa Agropecuária Brasileira, Brasília, DF, v. 37, n. 11, p. 1597-1604, nov. 2002. DOI: 10.1590/S0100-204X2002001100011.

SOUZA, M. S.; ALVES, S. S. V.; DOMBROSKI, J. L. D.; FREITAS, J. D. B.; AROUCHA, E. M. M. Comparação de métodos de mensuração de área foliar para a cultura da melancia. Pesquisa Agropecuária Tropical, Goiânia, v. 42, n. 2, p. 241-245, abr./jun. 2012. DOI: 10.1590/S1983-40632012000200016. 
